\title{
Virologic Evidences of Active Herpesviridae Infection in Children With Guillain-Barre Syndrome
}

\author{
Shahnaz Armin ${ }^{1,}$, , Farhad Mahvelati Shamsabadi ${ }^{1}$, Azadeh Kiomarci ${ }^{1}$, Farzane Jadali ${ }^{1}$ \\ ${ }^{1}$ Pediatric Infections Research Center, Shahid Beheshti University of Medical Sciences, Tehran, IR Iran \\ ${ }^{*}$ Corresponding author: Shahnaz Armin, Pediatric Infections Research Center, Mofid Children's Hospital, Tehran, IR Iran. Tel: +98-9121099758, Fax: +98-2122226941, E-mail: fmsham- \\ sa@yahoo.com.
}

Received: March 21, 2013; Revised: May 27, 2013; Accepted: July 04, 2013

\begin{abstract}
Background:The etiology of the Guillain-Barre syndrome(GBS) is not clear; in many cases, GBS is triggered by a bacterial or viral illness. Objectives: To evaluate the role of active infection with Herpesviridae group and its association with this syndrome we have investigated the cerebrospinal fluid (CSF) and serum of patients with GBS for detection of these viruses.

Patients and Methods: In a prospective and cross sectional study, CSF and serum samples were obtained from 15 consecutive patients admitted with GBS in the department of neurology in a university-affiliated children's hospital in Tehran. Patients had been diagnosed with GBS based on clinical and paraclinical findings. The level of IgM and IgG antibodies to Herpes simplex virus (HSV), Epstein-Barr virus (EBV), and Cytomegalovirus (CMV) were tested by enzyme linked immunosorbent assay, (ELISA) in CSF and serum. A highly sensitive polymerase chain reaction (PCR) assay was also used for virus detection in all samples.

Results: We detected viral DNA in 3 of 15 patients revealing current systemic or central nervous system(CNS) virus infection; in 2 cases CMV PCR had positive results in serum and in one case HSV PCR had positive findings in CNS.

Conclusions: The clinical significance of this finding has yet to be elucidated but we showed footprint of Herpes viruses in some patients with definite GBS.
\end{abstract}

Keywords: Guillain-Barre Syndrome; Herpesviridae; Enzyme-Linked Immunosorbent Assay; Polymerase Chain Reaction

\section{Background}

Guillain-Barre syndrome is considered the most common cause of acute flaccid paralysis (1). Based on Hughes and et al. report its annual incidence is 1-2 per 100000. Signs and symptoms of GBS include rapidly progressive tingling, numbness, weakness, and sometimes pain weakness which can be distal, proximal, or both. Tendon reflexes are eliminated early in the course of disease. Other symptoms are facial and bulbar weakness and sometimes ophthalmoplegia. The progressive phase usually lasts between 2 to 4 weeks. Recovery is gradually begin to develop after a few days or weeks and continues over several months (2).

Two-thirds of patients have a history of an infection in weeks before starting Guillain-Barre syndrome. Epidemiological evidence support associations of Campylobacter jejuni (3), Mycoplasma pneumonia, Cytomegalovirus, and Epstein-Barr virus with GBS (4-7). There are some reports of GBS following immunization with Influenza A (H1N1) monovalent vaccine $(8,9)$. Despite the multiplicity of antecedent infections, the popular hypothesis invokes cross reactivity between microbial and myelin antigens to ac- count for the disease (10).

Guillain-Barre is known as a syndrome rather than a disease because the main cause is still unknown (11). GBS may be related to direct virus invasion or immunologic process which is mediated by infiltration of cytotoxic CD8+ lymphocytes into neural tissue or deposition of antibody-antigen complex (12). Molecular similarity between the bacterial lipo-oligosaccharide and the human gangliosides is considered as an important cause of acute motor axonal type (13). The main sites for the antibody in this type are gangliosides GM1, GM1b, GD1a, and GalNAcGD1a which are expressed on the motor axolemma (14). Serologic criteria of active infection in serum and increase of immunoglobulin levels in cerebrospinal fluid (CSF), presumably due to synthesis of immunoglobulin in the central nervous system (CNS), has been reported in GBS (15). The development of symptoms in a few days to two weeks after infection supports the role of an immune reaction in GBS (15). Presence of IgM in the CSF is probably due to immunoglobulin synthesis within the CNS and a sign of acute infection; also detection of virus DNA by PCR, confirms the diagnosis of current infection. patients had positive PCR results for Herpesviridae.

Copyright (C) 2014, Pediartric Infections Research Center. This is an Open Access article distributed under the terms of the Creative Commons Attribution License (http://creativecommons.org/licenses/by/3.0), which permits unrestricted use, distribution, and reproduction in any medium, provided the original work is properly cited. 
Definite diagnosis of these infections makes it possible to propose specific treatment for these viruses. Some studies reported virus DNA detection in serum or CSF of patients with GBS and raised question about the role of active infections with these viruses in pathogenesis of GBS $(6,16-18)$. It is not yet clear whether antibiotic therapy has preventive effect on GBS. Yet despite treatment with intravenous immune globulin and plasma exchange disease morbidity and mortality are 5\%-10\% and 2\%-4\% respectively. Furthermore, because the available data are limited, it would be very interesting to explore whether antiviral therapy for Herpesviridae can prevent the development of GBS or can improve the prognosis of those with GBS in this population.

\section{Objectives}

Detection of Herpesviridae group, (CMV, EBV and HSV) in CSF and serum samples during neurological illness would support a close association between these infections and GBS. It was therefore the aim of the present study to investigate, by using highly sensitive polymerase chain reaction (PCR) assay, whether Herpesviridae group can be detected in the CSF of patients with GBS with serologic evidence for recent or past infection.

\section{Patients and Methods}

In a prospective and case series study, between May 2006 and January 2009, a total of 19 patients with GBS were admitted in the department of neurology in a university-affiliated children's hospital in Tehran. We included all patients with diagnosis of GBS based on accepted clinical criteria (19). Our patients had no fever at admission and had symmetric progressive paralysis, areflexia or hyporeflexia in the legs and arms, protein CSF level was $>40 \mathrm{mg} / \mathrm{dL}$ (mean, $172.9 \mathrm{mg} / \mathrm{dL}$ ), and mononuclear cell count of $>10$ cells $/ \mathrm{mm}^{3}$ (mean, 3.2 cells $/ \mathrm{mm}^{3}$ ). These patients had no known history of immunosuppression because Herpesviridae DNA might also be found frequently in these patients. No patients with neuropathy secondary to known recent immunization were included. We excluded patients who had associated systemic diseases, such as human immunodeficiency virus disease, systemic lupus erythematosus, or lymphoma, because these conditions could confound the association between virus infections and GBS. According to the above criteria $15 \mathrm{pa}$ tients were included in the study. A lumbar puncture was performed in all cases at the time of admission; the investigations were performed on the specimens obtained up to ten days after onset of neurological disease. The level of IgM and IgG antibodies to HSV, EBV, and CMV were tested by enzyme linked immunosorbent assay, (ELISA) on CSF and serum, (Kit used: Euroimmun Medizinische Labordiagnostika AG); Sera were tested at 1:10, 1:20 and 1:40 dilution for antibodies. The tests were performed as outlined by the manufacturer. The OD was determined using multiscan apparatus. Virus-specific PCR assay was performed on serum and CSF samples. The DNA was extracted by (viral DNA/RNA extraction Kit viral gene spin TM DNA. this comprises a $300 \mathrm{nM}$ concentration of oligonucleotide primers. PCR assay was performed for cycles as follows: 1 cycle of $12 \mathrm{~min}$ at $94^{\circ} \mathrm{C}, 35$ cycles of $1 \mathrm{~min}$ at $94^{\circ} \mathrm{C}, 1 \mathrm{~min}$ at $57^{\circ} \mathrm{C}, 2 \mathrm{~min}$ at $72^{\circ} \mathrm{C}$, and 1 cycle of $10 \mathrm{~min}$ at $72^{\circ} \mathrm{C}$. PCR products were examined by electrophoresis in $2 \%$ Agarose. For each positive sample PCR testing was repeated on different aliquot of the original sample. We classified viral infection as active infection when PCR and IgM had positive findings in the CSF or serum samples, (with or without detectable levels of IgG); recent infection when IgM and IgG levels had positive results with a negative PCR, and past infection when IgG was positive with negative results for IgM and PCR. All information was documented on a special form.

Parents of all patients admitted to the ward with GBS were asked to participate in the current study. Pretreatment serum and CSF samples were obtained at hospital admission and assayed for the presence of DNA and antibodies against HSV, CMV, and Epstein-Barr virus. No ethical approval was required for this study; clinical data collection, serum and CSF sampling and electrophysiological testing are parts of the routine current treatment and management in our hospital for patients suspicious for GBS. Results of our study did not have any effect on the treatment and management of patients.

\section{Results}

A total of 15 patients were hospitalized with GBS during three years. The mean $( \pm S D)$ age of the patients with GBS was $47.2 \pm 12.5$ months (range, $1-9$ years); $60 \%$ of them (9/15) were female.

CMV: Four cases, (26.6\%) (All female) had evidence of past CMV infection (with positive serum CMV-IgG). One female patient was diagnosed with recent infection (positive serum CMV-IgM and IgG) and 2 male cases (13.3\%) with active infection (positive CMV PCR and CMV-IgM, and IgG in serum sample). Although CMV DNA was not detected in the CSF of any patient with GBS, IgM antibody had positive results in CSF in 2 male cases (Table 1 ).

HSV: We found 2 cases (one male and one female) (13.3\%) of past HSV infection with positive results for serum IgG, negative HSV IgM and negative PCR. In the CSF, IgG was detected in 2 cases; one of them (an eight years old female) had active CNS infection, with CSF positive results for both IgM and PCR (Table 2).

EBV: Seven patients ( 4 female and 3 male) (46.6\%) had past EBV infection with positive results for serum IgG and negative IgM or PCR. Four patients (26.6\%) had positive results for IgG in CSF, and one (6.6\%) of them (a 19 months old age male) had positive result for IgM, revealing recent EBV CNS infection (Table 3). 
Table 1. IgG and IgM and Polymerase Chain Reaction (PCR) of Cytomegalovirus (CMV) in Serum and Cerebrospinal Fluid (CSF) of Patients

\begin{tabular}{|c|c|c|c|c|c|c|}
\hline Num. & Serum IgM & CSF IgM & Serum IgG & CSF IgG & Serum PCR & CSF PCR \\
\hline $\mathbf{1}$ & - & - & + & - & - & - \\
\hline 2 & - & - & + & - & - & - \\
\hline 3 & + & - & - & - & + & - \\
\hline 4 & - & + & - & + & - & - \\
\hline 5 & + & + & + & - & + & - \\
\hline 6 & - & - & - & - & - & - \\
\hline 7 & - & - & + & - & - & - \\
\hline 8 & + & - & + & - & - & - \\
\hline 9 & - & - & - & - & - & - \\
\hline 10 & - & - & + & - & - & - \\
\hline 11 & - & - & - & - & - & - \\
\hline 12 & - & - & - & - & - & - \\
\hline 13 & - & - & - & - & - & - \\
\hline 14 & - & - & - & - & - & - \\
\hline 15 & - & _- & _- & _- & _- & _- \\
\hline
\end{tabular}

Table 2. IgG and IgM and Polymerase Chain Reaction (PCR) of Herpes Simplex virus (HSV) in Serum and Cerebrospinal Fluid (CSF) of Patients

\begin{tabular}{|c|c|c|c|c|c|c|}
\hline Num. & Serum IgM & CSF IgM & Serum IgG & CSF IgG & Serum PCR & CSF PCR \\
\hline 1 & - & - & + & - & - & - \\
\hline 2 & - & - & - & - & - & - \\
\hline 3 & - & - & - & - & - & - \\
\hline 4 & - & - & - & - & - & - \\
\hline 5 & - & - & + & - & - & - \\
\hline 6 & - & - & - & - & - & - \\
\hline 7 & - & - & - & - & - & - \\
\hline 8 & - & - & - & - & - & - \\
\hline 9 & - & - & - & - & - & - \\
\hline 10 & - & - & - & - & - & - \\
\hline 11 & - & - & - & + & - & - \\
\hline 12 & - & - & - & - & - & - \\
\hline 13 & - & - & - & - & - & - \\
\hline 14 & - & + & - & + & - & + \\
\hline 15 & - & - & - & - & - & - \\
\hline
\end{tabular}

\section{Discussion}

Our data about EBV shows past systemic EBV infection in $7(46.6 \%)$ cases. In Volpi et al. study, EBV-specific IgM antibodies were detected in the serum of 8 of 100 patients with GBS in New Jersey, the USA (20); however, none of our patients showed detectable EBV-specific IgM antibodies. In another study, two of 99 patients showed serum IgM antibodies to EBV compared to two probable posi- tive sera from 99 age and sex-matched controls; these findings put the role of EBV in GBS under question (21). Conversely, based on interpretation of serology Link et al. found that 3 of 24 patients with Guillain-Barre syndromes had primary infection with Epstein-Barr virus and 11 had reactivated infection, and 10 were compatible with previous exposure (15). We diagnosed recent EBV CNS infection in one case (positive CSF IgG, IgM), this could support the 
Armin sh et al.

Table 3. IgG and IgM and Polymerase Chain Reaction (PCR) of Epstein-Barrvirus (EBV) in Serum and Cerebrospinal Fluid (CSF) of Patients

\begin{tabular}{|c|c|c|c|c|c|c|}
\hline Num. & Serum IgM & CSF IgM & Serum IgG & CSF IgG & Serum PCR & CSF PCR \\
\hline $\mathbf{1}$ & - & - & + & + & - & - \\
\hline 2 & - & - & - & + & - & - \\
\hline 3 & - & - & + & - & - & - \\
\hline 4 & - & - & + & + & - & - \\
\hline 5 & - & - & - & - & - & - \\
\hline 6 & - & - & + & - & - & - \\
\hline 7 & - & - & + & - & - & - \\
\hline 8 & - & + & - & + & - & - \\
\hline 9 & - & - & + & - & - & - \\
\hline 10 & - & - & - & - & - & - \\
\hline 11 & - & - & + & - & - & - \\
\hline 12 & - & - & - & - & - & - \\
\hline 13 & - & - & - & - & - & - \\
\hline 14 & - & - & - & - & - & - \\
\hline 15 & _- & _- & _- & _ & _- & _- \\
\hline
\end{tabular}

role of this virus in GBS; although the probability for passive diffusion of viral genome or IgM from the periphery into the CSF might occur in patients with increased permeability of the blood brain barrier (BBB), but in this case with positive results for IgM and IgG in CSF there, no footprints for systemic EBV infection were found. None of our cases had positive laboratory finding for current CNS infection, but Yasumasa Asai et al. reported a case of GBS with positive results for EBV PCR in the CSF (22).

Patients with a combination of HSV and GBS have been described only rarely. Bernsen et al., reported a case of Herpes simplex virus infection followed by Guillain-Barre syndrome; they used immunoblotting to detect Herpes simplex virus-specific antibodies in serum and cerebrospinal fluid (23). Also, Gerken et al. reported the association between HSV IgM-specific antibodies and Guillain-Barre syndrome (24). We detected HSV-IgG in the serum of 2 cases, thus demonstrating evidence of past infection. In an eight year old female in our study both HSV-IgM and HSV PCR had positive findings in the CSF, but HSV-IgM and IgG and PCR of serum had negative results, thus strengthening the association between isolated CNS infection by HSV complicated by GBS. As mentioned above passive transport of IgM or DNA to CSF due to increased permeability of the BBB is a possibility, but in this case because of negative serologic findings in serum, it is an unlikely explanation. The presence of HSV DNA in the CSF of patients with GBS could also be explained by reactivation of a persistent HSV infection during the course of GBS, but positive IgM antibody in CSF and negative IgG in serum is against an endogenous reactivation in this patient. We think this finding raises questions about the real nature of the underlying mechanisms in pathogenesis of GBS, because, in GBS, the main focus of the pathologic process is peripheral nerves, not the CNS.

CMV has been implicated as being a relevant antecedent infection for GBS, as some studies have detected IgM antibodies against CMV in 10\%-15\% of patients with GBS (18); this figure was $20 \%$ in our study. In a follow up study of 24 cases with GBS, Hans link et al. reported two patients with serological evidence of a primary cytomegalovirus infection, 2 with serology indicative of a reactivated infection, and 12 with titers compatible with previous exposure; 8 cases in their study remained seronegative (15). One of the reports supporting the role of active infection with CMV in the etiology of GBS comes from Steininger; he detected CMV DNA in 13 (31\%) of 42 CSF samples from patients with GBS, and nil from CSF samples collected from age-matched control subjects with acute encephalopathy. The presence of CMV in CSF may suggest that endogenous reactivation of CMV infection within the CNS does occur and that these patients may profit from antiviral therapy (18). In our study active CMV systemic infection (positive IgM, IgG and PCR in serum), was detected in 2 cases of GBS (13.3\%). We did not detect CMV DNA in CSF of our patients but detection of IgM in the CSF with simultaneous absence of laboratory criteria for systemic CMV infection (negative serum IgM, IgG, PCR) in one patient raises the possibility of in situ CNS infection and again supports the role of active CMV infection in GBS.

Conclusion: We used a highly sensitive PCR assay for testing CSF and serum samples from patients with acute GBS and found virus DNA in 3 of 15 patients tested (in 2 cases CMV PCR had positive results in serum and in one case HSV PCR was detected in CNS). Although the clinical 
significance of these findings has not yet been elucidated, these results point to an association between active Herpesviridae infection and GBS.

\section{Acknowledgements}

The authors would like to acknowledge the skillful technical assistance of pediatric infections research center staff.

\section{Authors' Contribution}

All authors contributed equally to this work.

\section{Financial Disclosure}

The authors declare no competing financial interests.

\section{Funding/Support}

There is no support for this study.

\section{References}

1. Hughes RA, Cornblath DR. Guillain-Barre syndrome. Lancet 2005;366(9497):1653-66.

2. Pritchard J, Hughes RA. Guillain-Barre syndrome. Lancet 2004;363(9427):2186-8

3. McCarthy N, Giesecke J. Incidence of Guillain-Barre syndrome following infection with Campylobacter jejuni. Am J Epidemiol. 2001;153(6):610-4

4. Gilden DH, Kleinschmidt-DeMasters BK, LaGuardia JJ, Mahalingam R, Cohrs RJ. Neurologic complications of the reactivation of varicella-zoster virus. $N$ Engl J Med. 2000;342(9):635-45

5. Ho M. The history of cytomegalovirus and its diseases. Med Microbiol Immunol. 2008;197(2):65-73.

6. Kuijf ML, Ang CW, van Doorn PA, Niesters HG, Jacobs BC. Presence or absence of cytomegalovirus in cerebrospinal fluid from patients with Guillain-Barre syndrome? J Infect Dis. 2006;193(10):1471-2.

7. Weinberg A, Bloch KC, Li S, Tang YW, Palmer M, Tyler KL. Dual infections of the central nervous system with Epstein-Barr virus. $J$ Infect Dis. 2005;191(2):234-7.

8. Choe YJ, Cho H, Bae GR, Lee JK. Guillain-Barre syndrome following receipt of influenza A (H1N1) 2009 monovalent vaccine in Korea with an emphasis on Brighton Collaboration case definition. Vaccine. 2011;29(11):2066-70.

9. Marin LF, Abrahao A, Carvalho FA, Santos WA, Dallalba CC, Barcelos LB, et al. Guillain-Barre syndrome associated with H1N1 vac- cination. Arq Neuropsiquiatr. 2010;68(6):974-5.

10. Willison HJ, Yuki N. Peripheral neuropathies and anti-glycolipid antibodies. Brain. 2002;125(Pt 12):2591-625

11. Satyanand Tyagi R, Yadav P, Saxena S. Management of Guillain Barre Syndrome- An Autoimmune Disorder: A Review. IJABPT. 2010;1(2):722-728.

12. Rabinstein AA. Guillain-Barré Syndrome. Open General Intern Med J. 2007;1:13-22.

13. Odaka M, Yuki N, Hirata K. Anti-GQ1b IgG antibody syndrome: clinical and immunological range.J Neurol Neurosurg Psychiatry. 2001;70(1):50-5.

14. Kuwabara S. Guillain-barre syndrome. Curr Neurol Neurosci Rep. 2007;7(1):57-62.

15. Link H, Wahren B, Norrby E. Pleocytosis and immunoglobulin changes in cerebrospinal fluid and herpesvirus serology in patients with Guillain-Barre syndrome. J Clin Microbiol. 1979;9(3):305-16

16. Figueiredo CA, Klautau GB, Afonso AM, Castrignano SB, Oliveira MI, Curti SP, et al. Isolation and genotype analysis of rubella virus from a case of Guillain-Barre syndrome. J Clin Virol. 2008;43(3):343-5.

17. Orlikowski D, Porcher R, Sivadon-Tardy V, Quincampoix IC, Raphael JC, Durand MC, et al. Guillain-Barre syndrome following primary cytomegalovirus infection: a prospective cohort study. Clin Infect Dis. 2011;52(7):837-44.

18. Steininger C, Popow-Kraupp T, Seiser A, Gueler N, Stanek G Puchhammer E. Presence of cytomegalovirus in cerebrospinal fluid of patients with Guillain-Barre syndrome. J Infect Dis. 2004;189(6):984-9.

19. Asbury AK, Cornblath DR. Assessment of current diagnostic criteria for Guillain-Barre syndrome. Ann Neurol. 1990;27 Suppl:S21-4.

20. Volpi A. Epstein-Barr virus and human herpesvirus type 8 infections of the central nervous system. Herpes. 2004;11 Suppl 2:120A-127A.

21. Winer JB, Hughes RA, Anderson MJ, Jones DM, Kangro H, Watkins RP. A prospective study of acute idiopathic neuropathy. II. Antecedent events. J Neurol Neurosurg Psychiatry. 1988;51(5):613-8.

22. Asai Y, Fujita R, Nakayasu H, Suzuki K, Kaneto T, Nakashima K. Urinary Retention as an Initial Symptom of Acute Meningo-Encephalo-Radiculitis in Epstein-Barr Virus Infection. Yonago Acta medica. 2008;51:83-8.

23. Bernsen HI, Van Loon AM, Poels RF, Verhagen WI, Frenken CW. Herpes simplex virus specific antibody determined by immunoblotting in cerebrospinal fluid of a patient with the GuillainBarre syndrome. J Neurol Neurosurg Psychiatry. 1989;52(6):788-91.

24. Gerken G, Trautmann F, Kohler H, Falke D, Bohl J, Nix W, et al. Rare association of herpes simplex virus IgM-specific antibodies and Guillain-Barre syndrome successfully treated with plasma exchange and immunosuppression. Klin Wochenschr 1985;63(10):468-74 